\title{
GLOBAL INFORMATION TECHNOLOGY Infrastructure in AdDressing the Problem of EnVironmental Degradation in Kenya
}

\author{
Patrick Owoche, Franklin Wabwoba and Alice Nambiro Wechuli \\ Department of Information Technology, Kibabii University, Kenya
}

\begin{abstract}
Information Technology (IT) infrastructure and related research communities can help tackle environmental challenges in developing countries through environmentally sustainable models of economic development. The paper sought to examine the status of current and emerging environmentally friendly technologies, equipment and applications in supporting programs that play a role in addressing environment degradation in Kenya. It also sought to underscore the role of IT in environmentally sustainable consumption. The paper examines what constitutes environment degradation and explores the negative effects of IT infrastructure on the environment. The consequences of E-waste on environment are discussed followed by green IT as part of the solution to environment degradation as a result of adoption of IT. The papers also discuss the available IT infrastructure that can be used to combat the challenges of environment degradation. The paper ends with possible IT infrastructure measures that can be used to mitigate environment degradation.
\end{abstract}

\section{KEYWORDS}

IT infrastructure, Environment degradation, Developing nations, Environmentally friendly technologies, IoT

\section{INTRODUCTION}

Though Kenya is experiencing rapid digital growth, there is need to appreciate that the nation's success should not come at the cost of future generations. The most central issue is ensuring digital growth grantees protecting the environment and the health of the citizens. Both developed and developing countries face many environmental challenges that are inclusive of climate change, improving energy efficiency, waste management, air pollution, water quality and scarcity, and loss of natural habitats and biodiversity. As scientific evidence of climate change continues to emerge and awareness to increase over the rapid accumulation of greenhouse gases, interest in the impact of ICTs on the environment has escalated, and along with it, research on their potential role in both contributing to and mitigating climate change [1]. 
Well-designed Information Technology infrastructure can have positive impacts on the environment, resulting in sustainable development. However, there is a dark side to digital infrastructural investments as occasionally they often lead to environmental degradation. Computers and other IT infrastructure consume significant amounts of electricity, placing a heavy burden on the electric grid and contributing to greenhouse gas emissions. Additionally, IT hardware poses environmental problems during both its production and its disposal [2] [3]. IT is a significant and growing part of the environmental problems in the current world [4]. Apart from minimizing the effect of IT infrastructure, IT provide an opportunity to make environmental protection more data-driven, empirical, and analytically rigorous [5]. Computers, wireless communications, remote sensing, and other technological breakthroughs are reshaping every facet of modern life by vastly increasing our capacity to collect, disseminate, and utilize information [5]. This information can be used to monitor and manage the environment. However wireless

communication is being rumored to be having some effects on human health though it is yet to be scientifically supported [6], [7].

This paper reviews the current literature on green computing with focus on global Information Technology infrastructure that can be used to address environmental degradation in Kenya.

\subsection{Environment Degradation}

Environmental degradation, including depletion of renewable and non-renewable resources and pollution of air, water and soils, can be a significant source of stress upon societies [8]. The World Bank's 1992 World Development Report cites deforestation, land degradation, water shortage and contamination, air pollution and the loss of biodiversity as some of the many environmental problems we face today in both developed and developing countries [9]. When carefully examined, then one notes that IT has its share of contributing to environmental degradation. Kenya faces a myriad of environmental issues, including deforestation, soil erosion, desertification, water catchment destruction, poaching, domestic and industrial pollution, land degradation, encroachment into fragile ecosystems, loss of biodiversity, degradation of aquatic ecosystems and resources, droughts, floods and landslides, invasive alien species [10] [11]. IT has the potential of addressing these environmental issues despite its share of environmental degradation.

Environmental degradation goes hand in hand with Eco-equity, which refers to the "equity between peoples and generations and, in particular, the equal rights of all peoples to environmental resources" (Gray and Bebbington 2000). At the heart of nearly all sustainability goals is the belief that there should be a fair distribution of resources both within and across generations (Gladwin et al. 1995). Eco-equity focuses on our social responsibility for the future generations who will bear the consequences of excessive consumption of scarce resources and environmental degradation.

Since independence, Kenya has continued to demonstrate her commitment to environmental management through various initiatives, among them the National Development Plans of 1974 and the National Environment Action Plan of 1994. These initiatives lead to the establishment of National Environment Management Authority (NEMA). NEMA puts more emphasis on 
monitoring and evaluation of the National Environment Action Plan to ensure their effective and efficient implementation as well as ensuring that environmental concerns are addressed and integrated in the development process [11]. IT infrastructure can support and shape the process of monitoring and evaluation. The purpose of monitoring and evaluation of environment is for us to understand the surroundings we live in so as to have the ability to foretell expected patterns and behavior of the environment in order to prepare better. Some of the approaches that can be used to manage and conserve the environment employ technology and at the heart of these technologies is IT. IT and its innovative derivatives can be used to address environmental degradation.

\section{Challenge To Developing Nations}

E-waste research conducted in Kenya reveals that there is high accumulation of old IT equipment in offices, homes and in repair shops because the owners are not aware off the equipment and whether or not it has any residual value that they can extract [25]. Developing countries and Kenya in particular, should develop an effective E-waste handling system. Responsible e-waste disposal (including recycling, refurbishing and reuse) couple with regulatory compliance can go a long way in enhancing Green computing. Environmental Regulations similar to the European Waste Electrical and Electronic Equipment (WEEE), the Restriction of the use of certain hazardous substances in electrical and electronic equipment (RoHS), Energy Star 4.0 should be put in place in Kenya and enforced.

\section{It AND ENVIRONMENTAL DEGRADATION}

International Telecommunication Union (ITU) [12] identified three levels in which adoption of IT can affect environment as:

i. Direct environmental effect of ICT product cycles, from their conception (including research and development) to the production, operation and disposal of ICTs. These impacts are mostly negative, even though research and the green imperative are driving the development of newer and more energy efficient technologies.

ii. Impacts due to increases in process efficiency because of using ICTs for business and everyday uses. Some examples include e-commerce, e-government and related applications. Smart motor systems (smart buildings, etc.), virtual meetings and other forms of dematerialization are other examples.

iii. Impact due to human behavioral change. They are due to efficiencies resulting from humans and society changing their behavior to take advantage of the efficiencies that ICTs provide, as well as the reduced environmental impacts that ICTs offer because of teleworking, teleconferencing, smart transportation systems, smart metering, and smart building designs, among others. Third order impacts may be the most important kind, but they are very difficult to measure, partly because they are not clearly understood and are only now beginning to be considered [13], [14]. 


\subsection{Understanding How IT Leads To Environmental Degradation}

IT acts both as tools to address sustainability imbalances and as the source of environmental challenges in themselves [3]. Each stage of a computing device's life, from its production, throughout its use, and into its disposal, presents environmental problems. All these directly or indirectly increase carbon dioxide emissions and affect the environment. The growing accumulation of greenhouse gases is changing the world's climate and weather patterns, creating droughts in some countries and floods in others. Electricity is a major cause of climate change. The coal or oil that helps generate electricity releases carbon dioxide, pollutants, and sulfur into the atmosphere [15]. These emissions can cause respiratory disease, smog, acid rain, and global climate change. Reducing electric power consumption is a key to reducing carbon dioxide emissions and their impact on our environment and global warming.

The total electrical energy consumption by servers, computers, monitors, data communications equipment, and cooling systems for data centers is steadily increasing. The use of data centers (DC) has been growing globally such that some market analysts are predicting the global DC power market alone could reach over $\$ 23$ billion by 2019 [16]. This increase in energy consumption results in increased greenhouse gas emissions. Each PC in use generates about a ton of carbon dioxide every year [4]. Computer components contain toxic materials. Increasingly, consumers discard a large number of old computers, monitors, and other electronic equipment two to three years after purchase, and most of this ends up in landfills, polluting the earth and contaminating water. The Kenya government is in the process of providing one laptop per child in primary schools. The is likely to increase the challenge of disposal since laptops, have short life cycles, becoming obsolete in only a few years [17].

The approximately 6,000 data centers in the United States, for instance, consumed roughly 61 billion kilowatt-hours (kWh) of energy in 2006 [18] [19]. The Department of Energy (DOE) reports that data centers consumed $1.5 \%$ of all electricity in the U.S. in 2006, and their power demand is growing $12 \%$ a year [18]. In that same year entire information and communication technologies (ICT) sector was estimated to be responsible for roughly $2 \%$ of global carbon emissions with data centers accounting for $14 \%$ of the ICT footprint [20]. In 2006 the cost of energy consumption by IT infrastructures in US was estimated as 4.5 billion dollars and was projected to double by 2011 [23]. The Natural Resource Defense Council of US estimates that in 2011, the US data centers consumed 76.4 billion kilowatt-hours and projects that by 2020 the U.S. data centers will consume roughly 140 billion kilowatt-hours of electricity annually [24].

The demand for data centers is rising in the East African [21] region, driven by factors such citizens' increasing use of data services; businesses looking to host their fast-growing digital information locally; governments moving towards e-governance; and the roll out of fibre infrastructure across Africa [22]. Regulations such as the Central Bank of Kenya's requirement that banks have disaster recovery centers outside their physical premise and the innovation culture fueled by huge push for development of mobile applications. These applications require data centers to host them. Source8 (2015) asserts that 
IT also contributes to environment degradation through disposal of electrical and electronic waste (e-waste). The total e-waste generated from computers, monitors and printers in Kenya was about 30,000 tonnes in 2007 [25]. Mureithi, et al.[25], asserts that there is high accumulation of old IT equipment in homes, offices, and repair shops because the owners are not aware of how to dispose off those equipment, and whether or not it has any residual value that they can extract. Some of such IT equipment find their way into the dump sites hence posing great environmental hazzards. Developing countries and countries in transition remain, despite having preventive legislation in-place, a dumping ground for e-waste from developed countries. This, added to an internal rise in the consumption and discard of electronic devices, makes the issue even more acute for Kenya [26].

The United Nations Environment Program \{UNEP\} (www.unep.org) estimates that 20 to 50 million tons of e-waste are generated worldwide each year, and this is increasing. UNEP in 2010 estimated at the annual rate of e-waste generation in Kenya stood at 2,500 tonnes from personal computers, 500 tonnes from printers and 150 tonnes from mobile phones [27]. This high rate of accumulation of e-waste stems not only from the rapid pace of emerging technologies but also from e-waste disposal by developed countries in the form of used electronic equipment with short life-spans. Some of the consequences of e-waste are:

i. Air pollution, especially when e-waste is burnt

ii. Waste management problem of non-biodegradable equipment

iii. Toxicity and radioactive nature of e-waste to the human, water, soil and animals

iv. Blockage of water runoff channels

v. Increased amount of waste

vi. Waste management disposal problem

E-waste has to be managed through a carefully organized system and existing actors should be part of the proposed system. Since IT contributes directly and indirectly to environmental degradation, in itself it has to be managed well to minimize its effect on environment. This is usually done through the concept of Green IT.

\subsection{Green It}

Green IT is a term used in addressing ecofriendly IT implementation. Green IT is ,therefore, the study and practice of designing, manufacturing, using, and disposing of computers, servers, and associated subsystems such as monitors, printers, storage devices, and networking and communications systems eco-efficiently and eco-effectively. Green IT also strives to achieve economic viability and improved system performance and use, while abiding by social and ethical responsibilities. Thus, green IT includes the dimensions of environmental sustainability, the economics of energy efficiency, and the total cost of ownership, which includes the cost of disposal and recycling [4]. Green IT can also be thought of as a systematic application of environmental sustainability criteria to the design, production, sourcing, use and disposal of the IT technical infrastructure as well as within the human and managerial components of the IT infrastructure in order to reduce IT, business process and supply chain related emissions and waste and improve energy efficiency [28]. These two definitions of Green IT provide an 
understanding that the adoption of Green IT is important in the management of business organizations and public institutions.

For sustainable development to be realized, there is need to address the negative effects of IT in itself. This is possible through the implementation of Green IT. Green IT benefits the environment by improving energy efficiency, lowering greenhouse gas emissions, using less harmful materials, and encouraging reuse and recycling of components of computing devices when they reach their refresh level [13] [14]. Factors such as environmental legislation, the rising cost of waste disposal, corporate images, and public perception give further impetus to the green IT initiative.

Some of the way in which Green IT can be realized are [29]; designing computing devices for environmental sustainability, energy efficient computing, green metrics, assessment tools and methodology, environment-related risk mitigation, use of renewable energy sources, eco-labeling of IT products and Cloud computing.

Energy-efficient computing can be achieved in several ways such as using Green Data Centers (GDC), server virtualization and cloud computing. GDC is a repository for the storage, management, and dissemination of data in which the mechanical, lighting, electrical and computer systems are designed for maximum energy efficiency and minimum environmental impact [30]. To maximize energy-efficient computing in GDC, virtualization software can be used. Virtualization software with power resource management features allows the administrator to power down inactive servers during non-peak hours so workload can be migrated and consolidated to fewer servers while others remain in standby or sleep mode.

Virtualization allows multiple operating system (OS) to run concurrently on a single computer where each "guest" OS is managed by a Virtual Machine Monitor (VMM). Virtualization technology allows one to create several Virtual Machines (VMs) on a physical server and, therefore, reduces amount of hardware in use and energy consumption and improves the utilization of resources. Through server virtualization organizations can manage energy efficiently thus mitigating environmental degradation. Virtualized datacenters and applications offered as services on a subscription is essentially clouds computing. Though some clouds are greener than others, it is agreed that cloud computing is generally more energy efficient and has a smaller carbon footprint than on premise server rooms [31]. Some studies show that Cloud computing can actually make traditional datacenters more energy efficient by using technologies such as resource virtualization and workload consolidation [32].

Cloud computing paradigm leverages virtualization technology and provides the ability to provision resources on-demand on the pay-as-you-go basis as opposed to the traditional approach where an organization purchases its own computing resources and deals with maintenance and upgrade of the outdated hardware, resulting in additional expenses. Organizations can outsource their computation needs to the Cloud, thereby eliminating the necessity to maintain own computing infrastructure. Cloud computing naturally leads to energy-efficiency by providing the following characteristics 
The aspect of Green IT metrics is also essential in addressing environmental degradation. As Peter Drucker is often quoted, if you can't measure it, you can't improve it, there must be tangible success metrics to tell when winning or losing in Green IT management. It is essential to construct power models that allow the system to know the energy consumed by a particular device, and how it can be reduced. To measure the unified efficiency of a datacenter and improve its' performance per-watt, the Green Grid has proposed two specific metrics known as the Power Usage Effectiveness (PUE) and Datacenter Infrastructure Efficiency (DciE) [32]. PUE and DCIE are most common metrics designed to compare the efficiency of datacenters. Equations 1 and 2 can be used to compute PUE and DciE.

$$
\begin{aligned}
\text { PUE } & =\frac{\text { IT Equipment Power }}{\text { Total Facility Power }} \ldots \ldots \ldots \ldots . . . \text { Eq. } 1 \\
\text { DciE } & =\frac{\text { IT Equipment Power }}{\text { Total Facility Power }} \times 100 \% \ldots . \text { Eq. } 2
\end{aligned}
$$

Here, the Total Facility Power is defined as the power measured at the utility meter that is dedicated solely to the datacenter power. The IT Equipment Power is defined as the power consumed in the management, processing, and storage or routing of data within the datacenter. Other measures include environment-related risk mitigation, use of renewable energy sources and Eco-labeling of IT products

To maximize the application of Green IT, the following measures can be used.

i. Green use. Reduce the energy consumption of computers and other information systems and use them in an environmentally sound manner.

ii. Green design. Design energy efficient and environmentally sound components, computers, servers, and cooling equipment.

iii. Green manufacturing. Manufacture electronic components, computers, and other associated subsystems with minimal or no impact on the environment.

iv. Green disposal. Refurbish and reuse old computers and properly recycle unwanted computers and other electronic equipment.

In addition, e-waste can be a valuable source for secondary raw materials. We should recycle old electronic systems by taking component material and reprocessing it into the same material or breaking it down into constituent materials for reuse.

\subsection{IT Measures For Addressing Environment Degradation}

Information systems have been the greatest force for productivity improvement in the last half century [33] and have the potential to create technology solutions focusing on key elements of the environmental imperative including air quality management and energy optimization for industries. Besides IT itself being green, it can support, assist, and leverage other environmental initiatives by offering innovative modeling, simulation, and decision support tools. This can be achieved through the use of software tools for analyzing, modeling, and simulating environmental impact, and environmental risk management. IT supported platforms for eco-management, such 
as tools for auditing and reporting energy consumption and savings and for monitoring greenhouse gas emissions. Tools such as environmental knowledge management systems, including geographic information systems and environmental metadata standards; urban environment planning tools and systems; technologies and standards for interoperable environmental monitoring networks and smart sensors networks; and integrating and optimizing existing environmental monitoring networks and new easy plug-in sensors can be used to for Eco management.

Advances in information technology are providing powerful new tools for combating air pollution and greenhouse gases. New networks of intelligent sensors act as our digital eyes on the world gathering data from across natural and manmade environments. At the same time, advances in machine learning have led to cognitive computing systems that ingest, understand and learn from this wealth of environmental data. Using predictive models, we not only can forecast what will happen next, but we can test hypotheses and answer questions like what would happen if we took a particular action or if conditions changed.

The word dematerialization is broadly used to characterize the decline over time in weight of the materials used in industrial products. It can also be characterized by decline in the embedded energy in industrial products [34]. With respect to IT, dematerialization is the process through which a paper based document gets converted to electronic format [35] and Dematerialization is the logical outcome of advances in IT infrastructure in which material needs are satiated. From environmental point of view, the use of less material translates in to smaller quantities of waste at both production and consumption phases of a product's life cycle.

Some of the ways that dematerialization can be used to minimize environment degradation are [36] [12]:

i. Digitization of materials, such as paper, CDs and video tapes, so that content is manipulated using strictly digital technologies

ii. Server and desktop virtualization

iii. Travel replacement technologies, such as telepresence technologies and other highdefinition, high-bandwidth video conferencing systems

iv. Replacement of brick and mortar retail outlets with digital malls, shops and storefronts

v. E-Government: Online government services replace the need for physical presence across a country or jurisdiction.

vi. Health: reduced need for travel

vii. E-Commerce: Online purchasing of goods and services that replaces the need for physical presence.

\section{Wireless Sensor Networks for Energy Saving}

WSN can be used in home automation system can result in energy saving and associated cost savings for a household [37]. For example following may be employed to achieve energy saving: 
- Scenes and timers: Energy savings can be achieved through the careful configuration of 'scenes' and timers to ensure that no more energy is consumed than is actually needed.

- Occupancy sensors: Infra-red or movement sensors can be used to switch on appliances, such as lights, only when a person is detected (and switch off when a person is no longer detected). As an example, this method may be very useful for controlling lights in a corridor or garage, or outside lights.

- Energy monitoring: The power consumption of an HA system may be monitored.

\section{It INFRASTRUCTURE KENYA CAN USE In ADDRESSING ENVIRONMENTAL DEGRADATION}

As the IT infrastructure advance so are the technologies that can be used to address environmental degradation in Kenya and the world at large. ITU identified the following Trends in ICT and ICT applications that can be used to sustain the environment [38]:

i. Growing number and types of remote sensing technologies and platforms \{Wireless sensor networks (WSN)\} [39]

ii. Growing processing power efficiency storage capacity and intelligent algorithms

iii. Growing broadband and wireless connectivity, grids and clouds

iv. Growing miniaturization and digitalization

A sensor network is a set of spatially distributed devices that reports the status of a physical item or environmental condition. It might report, for instance, temperature, air composition (to detect pollution), location and speed of a mobile object, contents of a package in transit, or the traffic on a link [40]. Autonomous wireless sensor networks interact with its environment independently and relay its information wirelessly with other nodes in the network [41] through the concept of Internet of Things (IoT). Wireless sensor networks facilitate monitoring and controlling of physical environments from remote locations with better accuracy [41].

WSN has good functions of data collection, transmission, and processing. A WSN generally consists of a large number of low-cost and low-power multifunctional sensor nodes that are deployed in a region of interest [12]. In WSN, the nodes communicate wirelessly over short distances and are capable of organizing themselves in an autonomous multi-hop mesh network. [42]. The data collected by the sensors is then sent to a base station where the data can be stored for analysis and processing.

IoT and in effect WSN can be used to address environment degradation in terms of monitoring, detection and controlling attributes that can be empirically sensed [43] through applications such as smart cities, home automation, and other natural environmental phenomenon.

Building and home automation technologies have usually been deployed only in high-level offices and luxury apartments [44]. However, with miniaturization, falling cost of computing devices coupled with advances in wireless communication among other things, smart homes are now a reality. For example, smart metering is becoming more popular for measuring energy consumption and transmitting this information to the energy provider electronically. This can be 
combined with other sensors and actuators within a building, thus forming a fully interconnected, smart environment. Sensors for temperature, humidity, smoke, light provide the necessary data to automatically adjust the comfort level and to optimize the use of energy for heating or cooling and also alert the concerned authority in case they go beyond acceptable levels.

IoT can also be used to develop smart cities in which the sensors provide data for monitoring, controlling and detecting environmental variables in real-time. Smart cities can have sensors to monitor things like noise, traffic congestion, water quality, water leakage, air pollution, radiation levels, and any other attribute of environment that can be detected empirically. The data collected from the sensors can be analyzed and be used in addressing environmental degradation in Kenya.

\section{WAY FORWARD FOR DEVELOPING NATIONS}

The impacts of IT infrastructure on the environment can be direct such the impacts of IT infrastructure themselves, like energy consumption and e-waste. Indirect effects of IT are things like the impacts of IT applications, such as intelligent transport systems, buildings and smart grids. IT infrastructure can also affect the environment in some ways such as the impacts enabled by the direct or indirect use of ICTs, such as greater use of more energy efficient transport.

Positive impacts can come from dematerialization and online delivery, transport and travel substitution, a host of monitoring and management applications, greater energy efficiency in production and use, and product stewardship and recycling. Negative impacts can come from energy consumption and the materials used in the production and distribution of ICT equipment, energy consumption in use directly and for cooling, short product life cycles and e-waste, and exploitative applications.

\section{REFFERENCES}

[1] A. V. Ospina and R. Heeks, "Unveiling the Links between ICTs \& Climate Change in Developing Countries: A Scoping Study," University of Manchester, Manchester, 2010.

[2] M. Adamson, R. Hamilton, K. Hutchison, K. Kazmierowski, J. Lau, D. Madejski and M. N, "Environmental Impact of Computer Information Technology in an Institutional Setting: A Case Study at the University of Guelph," University of Guelph, Ontario, 2005.

[3] F. Wabwoba and S. Mbugua, Green ICT implementation in developing nations : personnel perspective, Deutschland : Scholar's Press, 2014.

[4] S. Murugesan, "Harnessing Green IT: Principles and Practices," IEEE Computer Society, 2008.

[5] D. C. Esty, "'Environmental Protection in the Information Age"," 2004. [Online]. Available: http://digitalcommons.law.yale.edu/fss_papers/431.

[6] C. Sage and D. Carpenter, "Public health implications of wireless technologies," Pathophysiology Elsevier, pp. 1-14, 2009. 
International Journal of Information Technology Convergence and Services (IJITCS) Vol.9, No.1, February 2019

[7] M. Repacholi, E. Rongen, A. Staines and T. McManus, "Health Effects of Electromagnetic Fields," An Roinn Cumarsáide, Maraagus chainní Nádúrtha, Dublin, 2006

[8] United Nations, " environmental degradation and social integration," in UNRISD briefing paper no. 3, world summit for social development, 1994.

[9] World Bank, "World Development Report 1992: Development and the Environment," Oxford University Press, , New York, 1992.

[10] A. Duraiappah, "Poverty and Environmental Degradation: a Literature Review and Analysis CREED Working Paper Series No 8," International Institute for Environment and Development, London, 1996.

[11] NEMA, "National Environment action plan framework," National Environment Management Authority, Nairobi, 2009.

[12] A. Lambebo and S. Haghani, "A Wireless Sensor Network for Environmental Monitoring of Greenhouse Gases," in ASEE 2014 Zone I Conference, April 3-5, , Bridgpeort, CT, USA., 2014.

[13] OECD, " Policy responses to the economic crisis: investing in innovation for long-term growth.," OECD, Paris, 2009.

[14] R. Labelle, R. Rodschat, L. Pérez-Chavolla, M. Obiso and M. Maniewicz, "ITU e-Environment Toolkit and Readiness Index," International Telecommunication Union, Geneva, 2009.

[15] N. Armaroli and V. Balzani, "The Future of Energy Supply: Challenges and Opportunities," Angewandte Chemie International Edition 46(1-2), pp. 52-66, 2007.

[16] A. Schlichting, "A Review of Commercial Technologies and Recommendations for Application to Department of Defense Systems," The MITRE Corporation, McLean, 2016.

[17] N. Agrawal and K. N. Agarwal, "Current Trends in Green ICT," JOAAG, vol. 7, no. 1, pp. 71-85, 2012.

[18] P. Kurp, "Green Computing: Are you ready for a personal Energy Meter?," communications of the acm, 51 (10), 1 october 2008.

[19] R. R. Harmon and N. Auseklis, "Sustainable IT Services: Assessing the Impact of Green Computing Practices," in PICMET 2009 Proceedings,, Portland, 2009.

[20] P. P. Ray, "The green grid saga -- a green initiative to data centers: a review," Indian Journal of Computer Science and Engineering, 1 (4), pp. 333-339, 2012.

[21] D. Mbuvi, "Data center industry emerging in Kenya," CIO East Africa, 19 May 2011. [Online]. Available: http://cio.co.ke/news/main-stories/Data-center-industry-emerging-in-Kenya. [Accessed 28 June 2016]. 
International Journal of Information Technology Convergence and Services (IJITCS) Vol.9, No.1, February 2019

[22] Source8, "Four Trends- Sub-Saharan African Data Centres: The Sub-Saharan African Data Centre Landscape," Author, London, 2015.

[23] A. Beloglazov and Buyya, "R Energy Efficient Resource Management in Virtualized Cloud Data Centers," in 10th IEEE/ACM International Conference on Cluster, Cloud and Grid Computing, 2010.

[24] NRDC, " America's data centres are wasting huge amount of energy," Natural Resource Defense Council, New York, 2014.

[25] M. Mureithi, T. Waema, A. Wanjira, A. Finlay and M. Schluep, "E-Waste in Kenya: Baseline Assessment," in 19th Waste Management Conferenceof the IWMSA, Durban, 2008.

[26] IETC, "Policy Brief on E-waste: What, Why and How," UNEP's Division of Technology, Industry and Economics, Osaka, 2013.

[27] NEMA, "Guidelines for E-Waste Management in Kenya," National Environment Management Authority, Nairobi, 2011.

[28] A. Molla, V. Cooper and S. Pittayachawan, "IT and eco-sustainability: Developing and validating a green IT readiness model.," in Thirtieth International Conference on Information Systems, Phoenix, 2009.

[29] C.-H. Lee, C.-T. Chang, K.-S. Fan and T.-C. Chang, "Lee, C-H.; Chang, C-T.; Fan, K-S.; and Chang, T-C. 2004. An overview of recycling and treatment of scrap computers.," Journal of Hazardous Materials. B114, pp. 93-100., 2004.

[30] R. Bauer, "Building Green Data Centers: Towards best practices and technical considerations," Storage Networking Industry Association (SNIA), n.c, 2008.

[31] O. Whitney and J. Kennedy, "Is Cloud Computing Always Greener?," Natural Resources Defense Council, New York, 2012.

[32] S.Garg and R.Buyya, "Green Cloud computing and Environmental Sustainability," Harnessing Green IT: Principles and Practices, pp. 315-340, 2012.

[33] R. T. Watson, M.-C. Boudreau and A. J. Chen, "Information systems and environmentally sustainable development: energy informatics and new directions for the is community," MIS Quarterly 34 (1) , pp. 23-38, 2010.

[34] R. Herman, S. A. Adrekani and J. H. Ausubel, "Dematerialization," Technological Focusing and Social Change 38, pp. 333- 347, 1990.

[35] R. Raman, D. Pramod and V. Bharathi, "Information and communication technology based model for dematerialization of academic certificates for Indian educational systems," American Journal of Applied Sciences 11 (1), pp. 85-88, 2014.

[36] ITU, "ICTs for e-Environment: Guidelines for developing countries with a focus on climate change," ITU, Geneva, 2008. 
International Journal of Information Technology Convergence and Services (IJITCS) Vol.9, No.1, February 2019

[37] NXP, "ZigBee Home Automation User Guide," 20 February 2015. [Online]. Available : www.nxp.com.

[38] M.Obiso, "e-environment and the use of ICT for environmental monitoring," in ITU/ICTP 2nd Awareness Workshop "Relevance of Low Cost Wireless ICT Solutions for development", Trieste, 2009.

[39] ZTE, "ICT Development Trends (2014): Embracing the Era of Mobile-ICT," Author, 2014.

[40] V. Raghavan and H. Shahnasser, "mbedded Wireless Sensor Network for Environment monitoring," Journal of Advances in Computer Networks, 3( 1), pp. 13-17, 2015.

[41] K. K. Khedo, R. Perseedoss and A. Mungur, "A wireles sensor network air pollutionfor monitoring system," International Journal of wireless \& mobile Networks, 2(2), pp. 31-45, 2010.

[42] N. Giannopoulos, C. Giannopoulos and A. Kameas, "Design Guidelines for Building a Wireless Sensor Network for Environmental Monitoring," in 2009 Panhellenic Conference on Informatics, Corfu Greek, 2009.

[43] N. A. Somani and Y. Patel, "ZIGBEE: A LOW POWER WIRELESS," International Journal of Control Theory and Computer Modelling (IJCTCM) 2(3) DOI : 10.5121/ijctcm.2012.2303 27 , pp. 27-33, 2012.

[44] P.Guillemin, P. Friess, O. Vermesan, M. Harrison, H. Vogt, K. Kalaboukas, M. Tomasella, ,. K. Wouters, G. S and S. Haller, "Strategic Research Agenda," in Vision and Challenges for Realising the Internet of Things, Brussels, European Union, 2010, p. 51.

[45] W.Mungai, "Using ICTs for Poverty Reduction and Environmental Protection in Kenya: The "Mvironment" Approach," in A Developing Connection: Bridging the Policy Gap between the Information Society and Sustainable Development ISBN 1-895536-77-4, International Institute for Sustainable Development (IISD), 2005, pp. 43-85.

[46] J. Ahola, T. Ahlqvist, M. Ermes, J. Myllyoja and J. Savola, "ICT for Environmental Sustainability: Green ICT Roadmap," JULKAISIJA - UTGIVARE, Vuorimiehentie, 2010.

[47] D. Pamlin and E. Thorslund, " (2004). An outline for a sustainable e-strategy - Sweden and a central issue for the future," IT Forum, Mislo, 2004.

[48] J. Houghton, " ICT and the environment in developing countries: opportunities and developments," Centre for Strategic Economic Studies Victoria University, 2009.

[49] O. Vermesan and P. Friess, Internet of Things: Converging Technologies for Smart Environments and Integrated Ecosystems, Aalborg Denmark: River Publishers , 2013.

[50] United Nations, " United nations research institute for social development," 1994.

[51] Z. Yiming, Y. Xianglong, G. Xishan, Z. Mingang and W. Liren, " A Design of Greenhouse Monitoring \& Control System Based on ZigBee Wireless Sensor Network”,", IEEE journa1, 2007. 
International Journal of Information Technology Convergence and Services (IJITCS) Vol.9, No.1, February 2019

[52] D. Ye, D. Gong and W. Wang, "Application of Wireless Sensor Networks in Environmental Monitoring," in 2nd International Conference on Power Electronics and Intelligent Transportation System, 2009.

\section{AUTHORS}

Patrick Owoche is a Tutorial Fellow at Kibabii University Bungoma where he is pursuing a $\mathrm{PhD}$ in IT. He has an MSc in IT from Masinde Muliro University of Science and Technology (MMUST), a Certified Information and Communication Technologist (CICT). He also holds BEd Science (Maths \& Physics) from Egerton University, Diploma in Office System Technology from KTI and CCNA II.

Prof. Franklin Wabwoba is an Associate professor in Information Technology and Dean of the School of Computing and Informatics at Kibabii University (Kenya). He holds a $\mathrm{PhD}$ (Information Technology) from Masinde Muliro University of Science and Technology, Master of Science (Computer Applications) from Kenyatta University; Endorsement (Educational Management) from University of South Africa and Bachelor of Education (science: Mathematics and Computer Science) from Egerton University. He has taught Computer Science and Information Technology courses for many years. He has ICT industrial experience

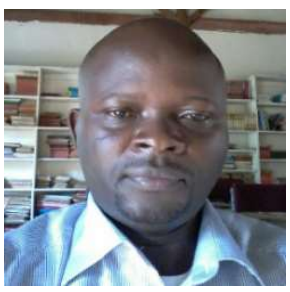
having worked with Mumias Sugar Company. He has presented several papers in scientific conferences and has many publications in referred journals as well as university level computing books. He has a strong research interest in green ICT, the impact of ICT applications on the community and integration of ICT into education. He is a professional member of the Association for Computing Machinery (ACM).

Dr. Nambiro Alice Wechuli received the BSc degree in Computer Science from Masinde Muliro University of Science and Technology, the MSc degree in Information Technology from Masinde Muliro University of Science and Technology, and $\mathrm{PhD}$ degree in Information Technology from Kibabii University. She is a lecturer in Information Technology department at Kibabii University, Kenya. Her research interests include data and information management and system security. She is a member of the

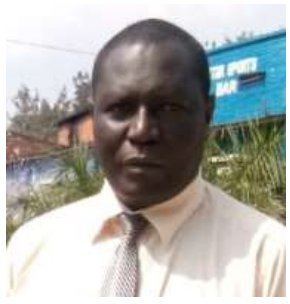
International Association of Engineers (IAENG). 